\title{
Multisyringe Flow Injection Analysis: State-of-the-Art and Perspectives
}

\author{
Marcela A. Segundo ${ }^{\dagger}$ and Luís M. Magalhães \\ REQUIMTE, Serviço de Química-Física, Faculdade de Farmácia, Universidade do Porto, \\ Rua Aníbal Cunha, 164, 4099-030 Porto, Portugal
}

\begin{abstract}
In the present paper, the characteristics (apparatus, manifold design, and operation mode) of multi-syringe flow injection analysis systems are discussed and critically compared to those of flow injection analysis and sequential injection systems. Furthermore, a survey of applications proposed until the present moment is presented, with special emphasis on implementation of in-line sample treatment.
\end{abstract}

(Received September 9, 2005; Accepted October 27, 2005)

1 Introduction
2 Apparatus and Flow Management Strategies
3 Sampling Strategies
4 Applications Using MSFIA System
$4 \cdot 1$ In-line gas diffusion
$4 \cdot 2$ In-line solid phase extraction
4.3 In-line liquid-liquid extraction
4.4 Microwave digestion
5 Conclusion
6 Acknowledgements
7 References 7 8

\section{Introduction}

The flow injection analysis (FIA) concept ${ }^{1}$ introduced in the middle 70 s together with the sequential injection analysis (SIA) approach $^{2}$ presented in the $90 \mathrm{~s}$ produced a dramatic increase in the interest of analytical chemists in flow analysis, both in terms of application to different matrices and also to the proposal of new ways of in-line sample manipulation.

Multi-syringe flow injection analysis (MSFIA) was introduced by Cerdà et al. in $1999^{3}$ as a robust alternative to its predecessor techniques, combining the multi-channel operation of FIA with the possibility of selecting only the exact volume of the sample and reagent required for analysis, as presented in SIA. The features of MSFIA systems allow the assembly of a flow network, connected to a detection system, where solutions from the different syringes can be either delivered to the flow system or returned to their own vessel, without interfering with the other channels.

In the present paper, the characteristics (apparatus, manifold design, operation mode) of MSFIA systems are discussed and critically compared to those of FIA and SIA systems. Furthermore, a survey of applications proposed until the present moment is given, with special emphasis on the implementation of in-line sample treatment.

\section{Apparatus and Flow Management Strategies}

MSFIA is based on the utilization of a multi-syringe burette,

\footnotetext{
† To whom correspondence should be addressed.

E-mail: msegundo@mail.ff.up.pt
}

depicted schematically in Fig. 1. It is a multiple-channel piston pump, containing up to four syringes, driven by a single motor of a usual automatic burette and controlled by computer software through a serial port. A two-way commutation valve is connected to the head of each syringe, allowing optional coupling to the manifold lines or to the solution reservoir.

The exchange options are often classified in off/on lines, where the "off" line is usually assigned to the vessels (for reagents, carrier or waste) and the "on" line is reserved to the manifold direction. ${ }^{4}$ Nevertheless, this option is not always followed, and in some cases the position is assigned in order to maintain the valves turned off most of the time to avoid overheating problems. ${ }^{5}$

Since the four syringes are driven by the same motor, all

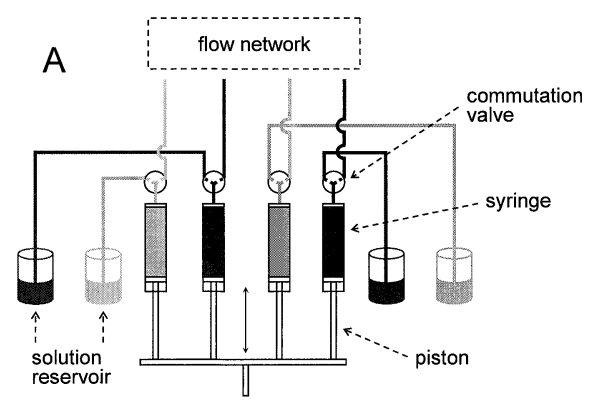

B

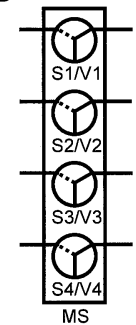

Fig. 1 Schematic representation of the multi-syringe apparatus, with indications of the different components (A), or simplified (B). MS, multi-syringe; $\mathrm{S}$, syringe; $\mathrm{V}$, commutation valve. 

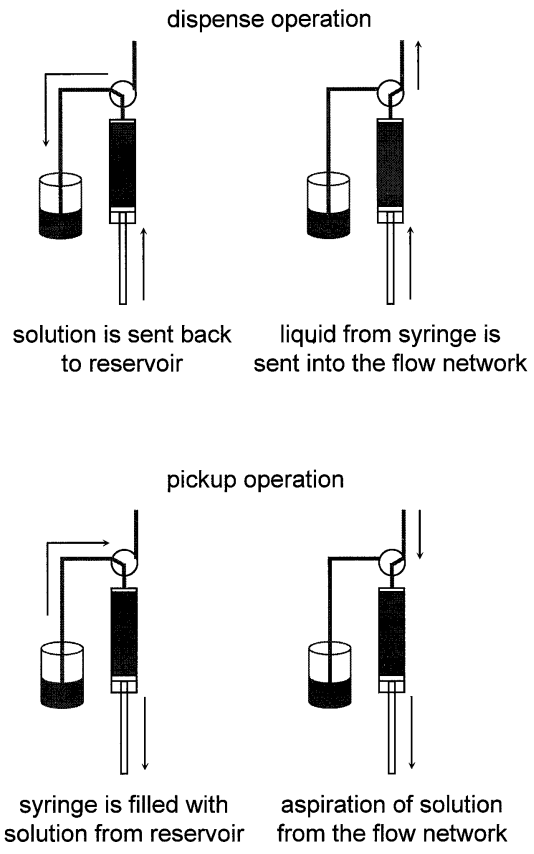

Fig. 2 Flow management possibilities for one syringe during the operation of a multi-syringe apparatus.

pistons move at once in the same direction either delivering liquids (dispense operation) or loading the syringes (pickup operation) with liquids. Considering that the valves can be placed in the "on" or "off" position, there are four possibilities for flow management, as depicted in Fig. 2. Therefore, when the pistons are moving upwards, it is possible to dispense liquid into the flow system, or send it back to its reservoir. This feature enables that only the necessary amount of reagent solution is introduced in the flow system. Furthermore, when the pistons are moving downwards, it is possible to refill the syringes with solutions present in the respective vessel or to aspirate solutions from the system, in order to fill an injection loop, for instance.

Syringes with different capacities may be used at the same time in the multi-syringe, bearing volumes of $0.5,1,2.5,5,10$ or $25 \mathrm{ml}$. Since the most recent equipment has the total piston displacement divided in 40000 steps, the minimum theoretical delivery/aspiration volume using a $0.5 \mathrm{ml}$ syringe is $0.0125 \mu \mathrm{l}$, corresponding to a motor step. In terms of precision, the coefficient of variation for the injection of volumes equal or larger than $20 \mu \mathrm{l}$ using a $2.5 \mathrm{ml}$ syringe is $<2 \%{ }^{6}$

Considering the different volumes of the available syringes, a wide range of flow rates can be used. For example, for a $10 \mathrm{ml}$ syringe, flow rates ranging from 0.57 to $30 \mathrm{ml} \mathrm{min}{ }^{-1}$ may be attained. ${ }^{6}$ Nevertheless, once the flow rate (and volume) is fixed for one syringe, it is also defined for other channels, depending on the ratio between the syringe capacities. For instance, if an instruction is sent to the multi-syringe in order to dispense $3 \mathrm{ml}$ at $2.0 \mathrm{ml} \mathrm{min}^{-1}$ from syringe 1 (capacity $10 \mathrm{ml}$ ), it will also dispense $1.5 \mathrm{ml}$ at $1.0 \mathrm{ml} \mathrm{min}^{-1}$ from syringe 2 (capacity $5 \mathrm{ml}$ ). This does not imply that both volumes are inserted in the flow system, since it depends on the position of the respective commutation valve.

Similarly to SIA systems, computer control is essential for operating MSFIA systems. Most of the systems described were developed using software written in Delphi and $\mathrm{C}++$, designated AutoAnalysis. This software provides a general platform for method development and comprehends a main application independent of the hardware configuration and a set of dynamic link libraries (DLL), according to the required instrumentation. ${ }^{7}$ This software also enables the integration of experimental data and treatment of the analytical signal. Nevertheless, it is also possible to control MSFIA systems using a software developed in BASIC language..$^{5,8}$

The presence of commutation valves coupled to each syringe enables the implementation of different strategies for flow management. It is possible to handle solutions as in FIA, by activating two valves simultaneously and connecting the two streams at a confluence point. It is also possible to implement the sandwich approach, where a sample is placed between two segments of reagent (or vice-versa) by commutating the two valves during the piston displacement. In this case, the mixture between solutions takes place at the boundaries of each segment, as occurs in SIA. Even the binary approach, frequently employed in multi-commutation flow systems, ${ }^{9}$ can be implemented in MSFIA systems by intercalating small slugs of solution using a commutation valve changing between the two positions at a frequency $>1 \mathrm{~Hz}$.

When compared to other strategies for automating analytical assays based on the "flow network" concept, such as multicommutation $^{9}$ and multi-pumping, ${ }^{10}$ MSFIA provides unique features, since the flow direction can be reversed. In flow systems based on this concept, the channels are connected to devices (solenoid valves or micro-pumps) that enable the access to the reagent(s), sample and carrier in a flexible way, resulting in $2^{n}$ possible combinations for flow management in multicommutation and multi-pumping flow systems, where $n$ is the number of streams involved. ${ }^{11}$ In the case of MSFIA systems, those combinations are expanded to $2^{n+1}$ (for $n=4$ ), since the flow direction can be reversed, resulting in twice the possibilities allowed by the other flow systems with the same number of channels. ${ }^{12}$

Finally, the construction of the MSFIA manifold is not restricted to the syringes and the respective commutation valves. The presence of four digital outputs, each capable of providing $12 \mathrm{~V} / 0.5 \mathrm{~A}$, allows the utilization of up to 12 additional commutation valves, also controlled through the multi-syringe apparatus.

\section{Sampling Strategies}

In MSFIA systems it is not feasible to introduce the sample into the system by filling one of the available syringes, since it would take a long time of washing steps to avoid carry-over between consecutive samples. ${ }^{13}$ Moreover, the amount of sample required for those washing steps would be considerably large, which is not compatible with samples that are scarce or expensive. Therefore, other devices, such as selection, ${ }^{14}$ injection, ${ }^{4}$ or commutation,,$^{15}$ valves must be incorporated to the manifold in order to provide access to the sample and standard solutions.

Two different strategies can be used to define the sample amount: volume-based and time-based strategies, ${ }^{16}$ as represented schematically in Fig. 3. The volume-based approach is based on the entrapment of a certain volume in a well-defined tube portion, which is subsequently pushed by a carrier, as occurs in FIA systems. The time-based mode relies on the aspiration or propulsion of a certain volume, defined by the flow rate and the time during that the pumping device is activated, as occurs in SIA. In fact, the volume-based approach is only applied in a few of the first MSFIA systems described. 


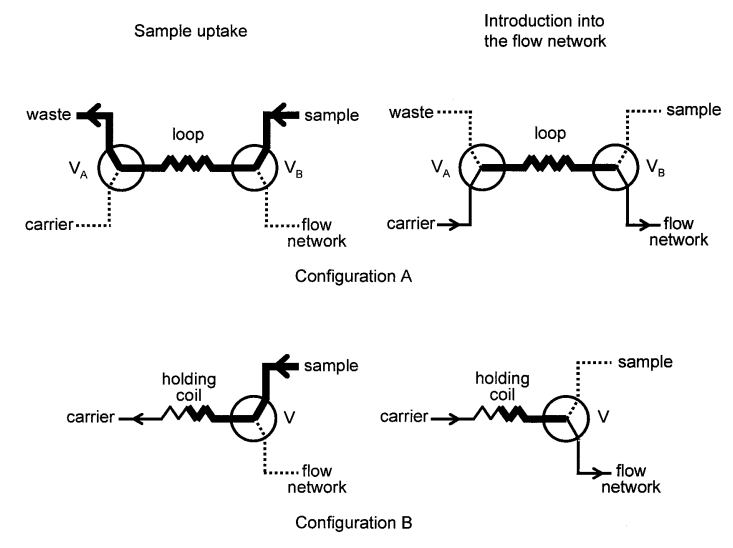

Fig. 3 Sampling operation based on volume-based (configuration A) and time-based (configuration B) strategies. V, commutation valve.

Undeniably, the time-based approach is far more flexible, since any alteration in the sample volume can be performed through software control, without any physical change required by volume-based configurations. The alteration of the sample volume through software control enabled the application of a dynamic concentration range when solid-phase extraction is performed. ${ }^{12,17}$ It also enabled the development of expert systems, where the analyzed volume was adjusted to the concentration present in the sample. ${ }^{18}$ Frequently, time-based sampling is performed by aspirating a large volume of sample, followed by the introduction of aliquots for further determination. This feature enhances the sample throughput, since it is not necessary to refill the syringes between each determination.

Recently, Segundo et al. ${ }^{19}$ studied whether the different sample strategies would affect the analytical signal, and not found evidence that the use of either volume or time-based sampling would improve the analytical features of the determinations tested. Furthermore, the order of steps in the analytical cycle was of crucial importance when performing time-based sampling, since they verified that any alteration in the flow direction affected the volume delivered in the subsequent step. Therefore, the introduction of a "dummy" step was recommended whenever the flow direction was changed before the sampling step.

\section{Applications Using MSFIA System}

Until now, about 30 articles were published describing the development and application of MSFIA for chemical analysis. This information was gathered from search engines available through ISI Web of Knowledge (September 2005). As listed in Table 1, about 22 species were determined in different type of samples. The majority of analysis was performed in environmental samples (water, soil extracts, fertilizers), but the application to process liquors from metallurgical industry, food, and biological samples was also described. Moreover, about half of the applications described rely on UV-visible spectrophotometric detection. $4,5,8,12,14,15,18,20-25$ Other types of detection systems were also applied in-line, namely those based on chemiluminescence, ${ }^{26-29}$ potentiometry, ${ }^{30}$ fluorometry, ${ }^{17,31}$ hydride generation atomic fluorescence spectrometry ${ }^{32-35}$ (HGAFS) and optical fiber reflectance. ${ }^{36-38}$ In the following sections, some features of MSFIA systems incorporating an inline sample treatment are discussed and compared to those obtained in FIA and SIA systems.

\subsection{In-line gas diffusion}

The introduction of gas-diffusion schemes in flow systems allows the removal of an analyte from a sample present in the donor channel to the portion of liquid present in the acceptor channel. In FIA systems, the operation of gas-diffusion devices is performed with the continuous flow of donor and acceptor streams through the respective channels. In SIA systems using the one-channel configuration (one pump, one selection valve, a holding coil connecting these elements), each channel is connected to a different port of the selection valve. Therefore, the operation of the gas-diffusion device is discontinuous, since only one channel can be connected to the central port of the selection valve. Furthermore, since the direction of flow can be changed in SIA systems, it is possible to enhance the yield of the gas-diffusion process by passing the same plug of sample several times through the donor channel, thus increasing the contact time between the sample and the acceptor liquid and allowing a renewal of the diffusion layer. Nevertheless, this strategy also increases the time necessary to complete an analytical cycle, providing lower sampling frequencies when compared to FIA.

In MSFIA systems both continuous and discontinuous operation can be accommodated without any physical change of the flow manifold owing to the possibility of connecting or disconnecting the syringes to the flow system in an independent way. This feature was implemented in the spectrophotometric determination of sulfur dioxide in wine samples, ${ }^{15}$ where each channel of the gas diffusion device was connected to a different syringe, containing a reagent (mixture of pararosaniline and formaldehyde prepared in-line) or carrier ( $\mathrm{HCl}$ solution). In this case, the discontinuous operation of SIA was applied to reduce the amount of reagent consumed by stopping the flow in the acceptor channel while the sample was sent through the donor channel. On the other hand, the simultaneous operation of both channels used in FIA was applied to send the reaction product from the acceptor channel to the detector while the donor channel was washed, enhancing the sample throughput by about $50 \%$ when compared with a similar SIA system. ${ }^{39}$

In-line gas diffusion was also applied to the spectrophotometric determination of ammonium in fertilizers and compost. ${ }^{21}$ Ammonium was converted into ammonia through the addition of an alkaline solution. The ammonia formed diffused to an acceptor solution containing a bromothymol blue solution, thus increasing the $\mathrm{pH}$ and the absorbance at $620 \mathrm{~nm}$. In this work, three strategies for flow management through the gas-diffusion unit were tried: 1) continuous operation of both channels; 2) continuous flow in the donor channel while the acceptor carrier was stopped; and 3) the acceptor carrier was stopped and the flow in the donor channel was reversed 5 times. The sensitivity was increased when the acceptor stream was static (about 3.4 and 2 times for operation of donor stream with and without flow reversals, respectively). Nevertheless, the injection throughput was reduced by about half when applying flow reversals in the donor stream. Similar results were found in a recent work dealing with the determination of sulfide, ${ }^{25}$ resorting to methylene blue chemistry.

\section{4-2 In-line solid phase extraction}

Solid phase extraction (SPE) is undoubtedly the most popular sample treatment implemented in-line in MSFIA systems, accounting for more than half of the applications comprising this type of operation. This is not a surprise since the multi- 
Table 1 Application of MSFIA

\begin{tabular}{|c|c|c|c|c|c|c|c|}
\hline Species & Detection system & Type of sample & In-line sample treatment & Application range & $\begin{array}{l}\text { Determination } \\
\text { rate/det } \mathrm{h}^{-1}\end{array}$ & $\begin{array}{c}\mathrm{RSD}, \\
\%\end{array}$ & Ref. \\
\hline Acidity & UV-vis & Process liquor & - & Up to $130 \mathrm{mmol} \mathrm{L}^{-1}$ & $78-100$ & $<5.4 \%$ & 20 \\
\hline Alkalinity & UV-vis & Process liquor & Dilution in a mixing chamber & $0.2-0.5 \mathrm{~mol} \mathrm{~L}^{-1}$ & $36-75$ & $<5 \%$ & 4 \\
\hline Aluminium(III) & Fluorometry & Drinking water & - & $10-500 \mu \mathrm{g} \mathrm{L}^{-1}$ & 154 & $<0.6 \%$ & 31 \\
\hline Ammonium & UV-vis & $\begin{array}{l}\text { Fertilizer and } \\
\text { compost }\end{array}$ & $\begin{array}{c}\text { Analyte separation by gas } \\
\text { diffusion }\end{array}$ & $5-70 \mathrm{mg} \mathrm{L}^{-1}$ & 20 & $<1.3 \%$ & 21 \\
\hline $\begin{array}{l}\text { Antimony (total) } \\
\text { and Sb(III) }\end{array}$ & HGAFS & $\begin{array}{l}\text { Water and lead } \\
\text { concentrate }\end{array}$ & - & $0.2-5.6 \mu \mathrm{g} \mathrm{L}^{-1}$ & 80 & $<4.6 \%$ & 32 \\
\hline Arsenic & HGAFS & $\begin{array}{l}\text { Water, fish muscle } \\
\text { and liver }\end{array}$ & - & $0.25-12 \mu \mathrm{g} \mathrm{L}^{-1}$ & 108 & $<4.9 \%$ & 33 \\
\hline Arsenic & HGAFS & $\begin{array}{l}\text { Drinking water, fish } \\
\text { muscle and liver }\end{array}$ & $\begin{array}{l}\text { Solid phase extraction } \\
\text { (Amberlite IRA-410 resin) }\end{array}$ & $0.05-2 \mu \mathrm{g} \mathrm{L}^{-1}$ & 30 & $<4.8 \%$ & 34 \\
\hline Boron (available) & UV-vis & Soil extract & - & $0.20-4.0 \mathrm{mg} \mathrm{L}^{-1}$ & 15 & $<1.4 \%$ & 5 \\
\hline Chloride & Potentiometry & $\begin{array}{l}\text { Mineral, tap and } \\
\text { waste water }\end{array}$ & - & $6-3500 \mathrm{~m} \mathrm{~L}^{-1}$ & 30 & $<0.8 \%$ & 30 \\
\hline Cobalt(II) & Chemilum. & $\begin{array}{l}\text { Pharmaceutical } \\
\text { preparation }\end{array}$ & - & $15 n g L^{-1}-5 \mu g L^{-1}$ & 180 & $<1.0 \%$ & 26 \\
\hline Glucose & Chemilum. & $\begin{array}{l}\text { Soft drink and fruit } \\
\text { juice }\end{array}$ & - & $90 \mu \mathrm{g} \mathrm{L}^{-1}-2.7 \mathrm{mg} \mathrm{L}^{-1}$ & 20 & $<2.5 \%$ & 27 \\
\hline Glucose & Chemilum. & $\begin{array}{l}\text { Soft drink, fruit juice } \\
\text { and human urine }\end{array}$ & - & $2.5-1000 \mu \mathrm{mol} \mathrm{L}^{-1}$ & 12 & $<2.5 \%$ & 28 \\
\hline Iron(III) & UV-vis & Process liquor & - & $1.0-6.4 \mathrm{mmol} \mathrm{L}^{-1}$ & $78-84$ & $<4.3 \%$ & 20 \\
\hline $\begin{array}{l}\text { Iron (total) and } \\
\mathrm{Fe}(\mathrm{II})\end{array}$ & UV-vis & Fertilizer & - & $1-35 \mathrm{mg} \mathrm{L}^{-1}$ & 68 & $<3.6 \%$ & 14 \\
\hline $\begin{array}{l}\text { Iron (total) and } \\
\mathrm{Fe}(\mathrm{III})\end{array}$ & UV-vis & Water & - & $\begin{array}{c}0.2-35 \mathrm{mg} \mathrm{L}^{-1}(\text { total Fe }) \\
0.1-20 \mathrm{mg} \mathrm{L}^{-1}(\mathrm{Fe}(\mathrm{III}))\end{array}$ & 60 & $<2 \%$ & 18 \\
\hline $\begin{array}{l}\text { Iron (total) and } \\
\mathrm{Fe}(\mathrm{III})\end{array}$ & UV-vis & Water & $\begin{array}{l}\text { Solid phase extraction } \\
\text { (chelating disks) }\end{array}$ & $0.019-3 \mu \mathrm{g}$ & 10 & $<2 \%$ & 18 \\
\hline Iron & UV-vis & Soil extract & - & $0.50-10.0 \mathrm{mg} \mathrm{L}^{-1}$ & 34 & $<2.0 \%$ & 5 \\
\hline $\begin{array}{l}\text { Iron (total) and } \\
\mathrm{Fe}(\mathrm{III})\end{array}$ & OFR sensor & Natural and seawater & $\begin{array}{l}\text { Solid phase extraction } \\
\text { (chelating disks) }\end{array}$ & $0.0012-0.25 \mu \mathrm{g}$ & 5 & $<2.2 \%$ & 36 \\
\hline $\begin{array}{l}\text { Iron (total) and } \\
\mathrm{Fe}(\mathrm{III})\end{array}$ & OFR sensor & Natural and seawater & $\begin{array}{l}\text { Solid phase extraction } \\
\text { (anion exchange disks) }\end{array}$ & $0.4-37.5 \mathrm{ng}$ & 7 & $<3.6 \%$ & 37 \\
\hline Nickel(II) & UV-vis & Process liquor & - & Up to $30 \mathrm{mg} \mathrm{L}^{-1}$ & 57 & - & 14 \\
\hline Nitrophenol & UV-vis & Water & Liquid-liquid extraction & $\begin{array}{l}2-43 \mu \mathrm{mol} \mathrm{L}^{-1} \\
4-110 \mu \mathrm{mol} \mathrm{L}^{-1} \\
0.4-10 \mu \mathrm{mol} \mathrm{L}^{-1}\end{array}$ & 11 & $<4 \%$ & 22 \\
\hline $\begin{array}{l}\text { Phenolic } \\
\text { compound (total) }\end{array}$ & UV-vis & Water & $\begin{array}{l}\text { Solid phase extraction } \\
\text { (Amberlite XAD-4 resin) }\end{array}$ & $0.010-6400 \mathrm{mg} \mathrm{L}^{-1}$ & $4-16$ & $<3.5 \%$ & 12 \\
\hline Phosphate & Chemilum. & Water & $\begin{array}{l}\text { Solid phase extraction } \\
\text { (NVP/DVB sorbent) }\end{array}$ & $5-50 \mu \mathrm{g} \mathrm{L}^{-1}$ & 11 & $<2.6 \%$ & 29 \\
\hline Phosphorus & UV-vis & Water & Microwave digestion & $3.00-36.0 \mathrm{mg} \mathrm{L}^{-1}$ & 12 & $<2.4 \%$ & 8 \\
\hline Phosphorus (available) & UV-vis & Soil extract & - & $0.75-15.0 \mathrm{mg} \mathrm{L}^{-1}$ & 15 & $<1.7 \%$ & 23 \\
\hline Selenium & HGAFS & $\begin{array}{l}\text { Drinking water and } \\
\text { sea lettuce }\end{array}$ & - & $0.1-3.5 \mu \mathrm{g} \mathrm{L}^{-1}$ & 84 & $4.6-7 \%$ & 35 \\
\hline $\begin{array}{l}\text { Strontium } \\
\text { (stable) }\end{array}$ & ICP-AES (off-line) & Water, milk and soil & $\begin{array}{l}\text { Solid phase extraction } \\
\text { (Sr-Resin) }\end{array}$ & $10-40 \mu \mathrm{g} \mathrm{L}^{-1}$ & - & $<2 \%$ & 40 \\
\hline $\begin{array}{l}\text { Strontium } \\
\text { (radioactive) }\end{array}$ & $\begin{array}{l}\text { Beta emission } \\
\text { counter (off-line) }\end{array}$ & Water, milk and soil & $\begin{array}{l}\text { Solid phase extraction } \\
\text { (Sr-Resin) }\end{array}$ & $>0.01 \mathrm{~Bq}$ & - & - & 40 \\
\hline Sulfide & UV-vis & Water & - & $0.2-2.0 \mathrm{mg} \mathrm{L}^{-1}$ & 45 & $<1.5 \%$ & 24 \\
\hline Sulfide & UV-vis & Waste water & $\begin{array}{l}\text { Analyte separation by gas } \\
\text { diffusion }\end{array}$ & $0.5-20 \mathrm{mg} \mathrm{L}^{-1}$ & 13 & $<0.8 \%$ & 25 \\
\hline Sulfide & OFR sensor & $\begin{array}{l}\text { Freshwater, seawater } \\
\text { and wastewater }\end{array}$ & $\begin{array}{c}\text { Solid phase extraction } \\
\text { (C18 disks) }\end{array}$ & $20-200 \mu \mathrm{g} \mathrm{L}^{-1}$ & 8 & $<0.7 \%$ & 38 \\
\hline $\begin{array}{l}\text { Sulfur dioxide } \\
\text { (free and total) }\end{array}$ & UV-vis & Wine & $\begin{array}{c}\text { Analyte separation by gas } \\
\text { diffusion }\end{array}$ & $\begin{array}{c}2-75 \mathrm{mg} \mathrm{L}^{-1} \text { (free) } \\
10-250 \mathrm{mg} \mathrm{L}^{-1} \text { (total) }\end{array}$ & $25-30$ & $<3.2 \%$ & 15 \\
\hline Warfarin & Fluorometry & Water & $\begin{array}{c}\text { Solid phase extraction (C18 } \\
\text { modified silica gel beads) }\end{array}$ & $50 \mathrm{ng} \mathrm{L}{ }^{-1}-64 \mu g \mathrm{~L}^{-1}$ & 12 & $<2 \%$ & 17 \\
\hline Yttrium (stable) & ICP-AES (off-line) & $\begin{array}{l}\text { Mineral and tap } \\
\text { water, human blood } \\
\text { and urine }\end{array}$ & $\begin{array}{l}\text { Liquid-liquid extraction } \\
\text { (HDEHP adsorbed on C18 } \\
\text { support) }\end{array}$ & $0.1-1000 \mathrm{mg} \mathrm{L}^{-1}$ & 3 & $<2.3 \%$ & 41 \\
\hline $\begin{array}{l}\text { Yttrium } \\
\text { (radioactive) }\end{array}$ & $\begin{array}{l}\text { Beta emission } \\
\text { counter (off-line) }\end{array}$ & $\begin{array}{l}\text { Mineral and tap } \\
\text { water, human blood } \\
\text { and urine }\end{array}$ & $\begin{array}{l}\text { Liquid-liquid extraction } \\
\text { (HDEHP adsorbed on C18 } \\
\text { support) }\end{array}$ & $>0.05 \mathrm{~Bq}$ & $<1$ & - & 41 \\
\hline
\end{tabular}

OFR, optical fiber reflectance; HDEHP, di-2-ethylhexylphosphoric acid; NVP/DVB, $N$-vinylpyrrolidone/divinylbenzene; HGAFS, hydride generation atomic fluorescence spectrometry; Chemilum., chemiluminescence; ICP-AES, inductively coupled plasma-atomic emission spectroscopy; UV-vis, ultra-violet/visible spectrophotometry. 
channel operation offered by multi-syringe and the discontinuous flow attained through the commutation valves provides unique features for implementing SPE protocols. Among them is the possibility of accommodating a loading solution and an eluent in different syringes, and by activating the respective commutation valve to change the solution that passes through the solid-phase extractant.

Moreover, the application of time-based sampling enables the establishment of calibration based on the mass of the analyte retained in the extractant phase. This approach may also expand the concentration working range, since different sample volumes can be used. Those features were implemented in the MSFIA systems described for the spectrophotometric determination of warfarin ${ }^{17}$ and total phenolic compounds ${ }^{12}$ in water. In both cases, calibration was performed in a wide interval, covering about 3 decades of concentration.

The solid-phase extractants applied in MSFIA systems were either commercial resins or disks. The resins were packed in tubular reactors and connected to the flow network. ${ }^{12,29,34,40}$ Generally, the analyte was retained and preconcentrated in the sorbent, and subsequently eluted before the detection step. In the determination of arsenic using HGAFS, ${ }^{34}$ borohydride and arsenic were sequentially retained in Amberlite IRA-410 resin. They were eluted before detection by the passage of an acid solution, causing the formation of arsine and hydrogen. In the determination of stable and radioactive strontium, ${ }^{40}$ the analyte was retained in a Sr-resin and eluted using $0.05 \mathrm{~mol} \mathrm{l}^{-1} \mathrm{HNO}_{3}$ before off-line detection.

A different strategy was adopted in the determination of phosphate using chemiluminescence detection. ${ }^{29}$ In this case, the solid phase ( $N$-vinylpyrrolidone/divinylbenzene copolymeric beads) was placed in front of the window of the photomultiplier tube. The adopted protocol included the in-line formation of the vanadomolybdophosphate species, followed by its retention in the sorbent. The detection of the retained heteropolyacid was based on the oxidation of luminol, with subsequent light emission. The elution was performed after detection using methanol before the next analytical cycle.

Solid-phase extraction was also performed in MSFIA systems using the extractant phase in the disk format. This format can offer several advantages over the conventional resin, such as the application of higher flow rates, and a lower back-pressure. The operation of this support can be similar to that performed with resins in packed reactors, as described by Pons et al. for the determination of trace levels of iron. ${ }^{18}$ This determination was based on the detection of the complex iron(III)-thiocyanate after the elution of iron from the chelating disk and the subsequent mixture with an ammonium thiocyanate stream. Those disks were also used to construct optical-fiber reflectance sensors, incorporated in MSFIA systems and applied for the speciation of iron ${ }^{36,37}$ and the determination of sulfide traces in water samples. ${ }^{38}$

\section{4-3 In-line liquid-liquid extraction}

The incorporation of liquid-liquid extraction schemes in MSFIA systems was described for the simultaneous spectrophotometric determination of 2-, 3- and 4-nitrophenol in water ${ }^{22}$ and for the extraction of yttrium from various samples. ${ }^{41}$

The flow system described by Miró et al. for the determination of nitrophenols ${ }^{22}$ relied on a dual wetting-film extraction/back-extraction approach to perform in-line analyte extraction from an aqueous medium to an organic solvent (1chlorobutane in octanol), that formed a thin, pseudo-stationary organic film that adhered to the inner walls of the extraction coil. The preconcentrated analytes were then eluted into a small solution segment and conducted to the detection system. This approach was first implemented in a SIA system, ${ }^{42}$ but problems related to air-bubble formation during aspiration of the organic solvent were reported. In the MSFIA manifold, this problem was solved by propelling organic solvents directly from the syringes. The manipulation of organic solvents using MSFIA offers other advantages when compared to FIA and SIA, avoiding the utilization of expensive tubes necessary in peristaltic pumps when propelling these solvents.

Furthermore, the determination frequency was significantly enhanced (about 3 times) by placing two extraction coils in the manifold. These coils were easily accessed by the solution present in any syringe using an ingenious configuration employing 4 commutation valves.

Liquid-liquid extraction was also carried out for the preconcentration of stable and radioactive yttrium by using di-2ethylhexylphosphoric acid adsorbed on a C18 support. ${ }^{41}$ The proposed manifold allowed an in-line coating of the solid support. The liquid coating could be reused at least ten times, or renewed after a single determination by passing ethanol through the $\mathrm{C} 18$ column. Although in-line detection was not implemented, the manual handling of radioactive samples was avoided and waste generation was reduced compared to the batch procedures.

\subsection{Microwave digestion}

In-line microwave digestion has been implemented using FIA $^{43}$ and SIA. ${ }^{44}$ Generally, in FIA systems, a sample mixed with acid or other reagents flows through a tubular reactor, placed inside the microwave digestor, before reaching the detection system or filling the loop of an injection valve. Using this approach, bubble formation often occurs and debbublers or cooling coils are usually adopted to circumvent their interference in the detection systems. In SIA systems incorporating microwave digestion, this step takes place in a "digestion bomb", a low-volume chamber (containing up to 1 $\mathrm{ml}$ ) placed inside the digestor and connected to one of the lateral ports of the selection valve. This configuration and the discontinuous operation of the chamber avoids the introduction of air bubbles in the flow system.

In the MSFIA system described for the determination of phosphorus in water ${ }^{8}$ the advantages provided by discontinuous operation of the digestion bomb were associated to the multichannel operation provided by FIA. By activating 2 syringes, sample and digestion solutions containing $\mathrm{K}_{2} \mathrm{~S}_{2} \mathrm{O}_{8}$ and $\mathrm{H}_{2} \mathrm{SO}_{4}$ were sent simultaneously to the digestion bomb. After digestion, phosphate was determined in aliquots drawn from the digestion bomb, using the molybdenum blue reaction. Finally, all flow systems were washed and prepared for the next analytical cycle using all of the syringes available and an auxiliary peristaltic pump.

\section{Conclusion}

Although described for the first time about five years ago, MSFIA was successfully applied for the development of novel flow methodologies, accomplishing the determination of more than 20 different species. The utilization of several types of detection systems also shows the potential of MSFIA to automate a vast range of analytical procedures. Furthermore, the implementation of an in-line sample treatment also shows its potential for assembling robust analyzers to perform not only the determination step, but also the tedious and time-consuming treatments existing before that. 
Some unique features provided by MSFIA systems are still under- or unexploited. Recently, Miró et al. pointed out the potential of combining the discontinuous operation of MSFIA with chemiluminescence detection. ${ }^{45}$ Furthermore, the development of expert flow analyzers should also be pursued, since computer control is inherent to MSFIA.

\section{Acknowledgements}

We acknowledge Prof. Víctor Cerdà and all people from his group (University of Balearic Islands) for sharing their experience and knowledge about this subject throughout these years.

\section{References}

1. J. Ruzicka and E. H. Hansen, Anal. Chim. Acta, 1975, 78, 145.

2. J. Ruzicka and G. D. Marshall, Anal. Chim. Acta, 1990, 237,329 .

3. V. Cerdà, J. M. Estela, R. Forteza, A. Cladera, E. Becerra, P. Altimira, and P. Sitjar, Talanta, 1999, 50, 695.

4. F. Albertús, B. Horstkotte, A. Cladera, and V. Cerdà, Analyst, 1999, 124, 1373.

5. D. M. C. Gomes, M. A. Segundo, J. L. F. C. Lima, and A. O. S. S. Rangel, Talanta, 2005, 66, 703.

6. M. Miró, V. Cerdà, and J. M. Estela, Tre. Anal. Chem., 2002, 21, 199.

7. E. Becerra, A. Cladera, and V. Cerdà, Lab. Robot. Autom., 1999, 11, 131.

8. M. I. G. S. Almeida, M. A. Segundo, J. L. F. C. Lima, and A. O. S. S. Rangel, Talanta, 2004, 64, 1283.

9. B. F. Reis, M. F. Giné, E. A. G. Zagatto, J. L. F. C. Lima, and R. A. Lapa, Anal. Chim. Acta, 1994, 293, 129.

10. R. A. S. Lapa, J. L. F. C. Lima, B. F. Reis, J. L. Santos, and E. A. G. Zagatto, Anal. Chim. Acta, 2002, 466, 125.

11. F. R. P. Rocha, B. F. Reis, E. A. G. Zagatto, J. L. F. C. Lima, R. A. S. Lapa, and J. L. M. Santos, Anal. Chim. Acta, 2002, 468, 119.

12. H. M. Oliveira, M. A. Segundo, S. Reis, and J. L. F. C. Lima, Microchim Acta, 2005, 150, 187.

13. V. Cerdà, J. Flow Injection Anal., 2003, 20, 203.

14. F. Albertús, A. Cladera, E. Becerra, and V. Cerdà, Analyst, 2001, 126, 903.

15. M. A. Segundo, A. O. S. S. Rangel, A. Cladera, and V. Cerdà, Analyst, 2000, 125, 1501.

16. J. Ruzicka and E. H. Hansen, "Flow injection analysis", 2nd ed., 1988, John Wiley \& Sons, New York.

17. G. Armas, M. Miró, J. M. Estela, and V. Cerdà, Anal. Chim. Acta, 2002, 467, 13.

18. C. Pons, R. Forteza, and V. Cerdà, Anal. Chim. Acta, 2004, 524,79 .

19. M. A. Segundo, H. M. Oliveira, J. L. F. C. Lima, M. I. G.
S. Almeida, and A. O. S. S. Rangel, Anal. Chim. Acta, 2005, 537, 207.

20. F. Albertús, A. Cladera, and V. Cerdà, Analyst, 2000, 125, 2364.

21. J. Klimundová, R. Forteza, and V. Cerdà, Intern. J. Environ. Anal. Chem., 2003, 83, 233.

22. M. Miró, A. Cladera, J. M. Estela, and V. Cerdà, Anal. Chim. Acta, 2001, 438, 103.

23. M. I. G. S. Almeida, M. A. Segundo, J. L. F. C. Lima, and A. O. S. S. Rangel, Intern. J. Environ. Anal. Chem., 2005, 85, 51.

24. L. Ferrer, G. Armas, M. Miró, J. M. Estela, and V. Cerdà, Talanta, 2004, 64, 1119.

25. G. Armas, L. Ferrer, M. Miró, J. M. Estela, and V. Cerdà, Anal. Chim. Acta, 2004, 524, 89.

26. N. Pizà, M. Miró, G. Armas, E. Becerra, J. M. Estela, and V. Cerdà, Anal. Chim. Acta, 2002, 467, 155.

27. N. Pizà, M. Miró, J. M. Estela, and V. Cerdà, Anal. Chem., 2004, 76, 773.

28. M. Manera, M. Miro, J. M. Estela, and V. Cerdà, Anal. Chim. Acta, 2004, 508, 23.

29. I. P. A. Morais, M. Miró, M. Manera, J. M. Estela, V. Cerdà, M. R. S. Souto, and A. O. S. S. Rangel, Anal. Chim. Acta, 2004, 506, 17.

30. A. Andrade-Eiroa, J. A. Erustes, R. Forteza, V. Cerdà, and J. L. F. C. Lima, Anal. Chim. Acta, 2002, 467, 25.

31. G. Armas, M. Miró, A. Cladera, J. M. Estela, and V. Cerdà, Anal. Chim. Acta, 2002, 455, 149.

32. N. V. Semenova, L. O. Leal, R. Forteza, and V. Cerdà, Anal. Chim. Acta, 2005, 530, 113.

33. N. V. Semenova, L. O. Leal, R. Forteza, and V. Cerdà, Anal. Chim. Acta, 2002, 455, 277.

34. L. O. Leal, N. V. Semenova, R. Forteza, and V. Cerdà, Talanta, 2004, 64, 1335.

35. N. V. Semenova, L. O. Leal, R. Forteza, and V. Cerdà, Anal. Chim. Acta, 2003, 486, 217.

36. C. Pons, R. Forteza, and V. Cerdà, Anal. Chim. Acta, 2005 , 528, 197.

37. C. Pons, R. Forteza, and V. Cerdà, Talanta, 2005, 66, 210.

38. L. Ferrer, G. Armas, M. Miró, J. M. Estela, and V. Cerdà, Analyst, 2005, 130, 644.

39. M. A. Segundo and A. O. S. S. Rangel, Anal. Chim. Acta, 2001, 427, 279.

40. Y. Fajardo, E. Gómez, F. Mas, F. Garcias, V. Cerdà, and M. Casas, Appl. Radiat. Isotopes, 2004, 61, 273.

41. Y. Fajardo, E. Gómez, F. Garcias, V. Cerdà, and M. Casas, Anal. Chim. Acta, 2005, 539, 189.

42. A. Cladera, M. Miró, J. M. Estela, and V. Cerdà, Anal. Chim. Acta, 2000, 421, 155.

43. M. Burguera and J. L. Burguera, Quim. Anal., 1996, 15, 112.

44. C. C. Oliveira, E. A. G. Zagatto, A. N. Araújo, and J. L. F. C. Lima, Anal. Chim. Acta, 1998, 371, 57.

45. M. Miró, J. M. Estela, and V. Cerdà, Anal. Chim. Acta 2005, 541, 57. 